\title{
Occurrence of Kelvin-Helmholtz Billows in Sea-breeze Circulations
}

Article

Accepted Version

Plant, R. S. and Keith, G.J. (2007) Occurrence of KelvinHelmholtz Billows in Sea-breeze Circulations. Boundary-Layer Meteorology, 122 (1). pp. 1-15. ISSN 0006-8314 doi: https://doi.org/10.1007/s10546-006-9089-x Available at https://centaur.reading.ac.uk/787/

It is advisable to refer to the publisher's version if you intend to cite from the work. See Guidance on citing.

To link to this article DOI: http://dx.doi.org/10.1007/s10546-006-9089-x

Publisher: Springer

Publisher statement: The original publication is also available at springerlink.com

All outputs in CentAUR are protected by Intellectual Property Rights law, including copyright law. Copyright and IPR is retained by the creators or other copyright holders. Terms and conditions for use of this material are defined in the End User Agreement.

\section{www.reading.ac.uk/centaur}

\section{CentAUR}

Central Archive at the University of Reading

Reading's research outputs online 


\title{
Occurrence of Kelvin-Helmholtz Billows in Sea Breeze Circulations
}

\author{
R. S. Plant (r.s.plant@rdg.ac.uk) and G. J. Keith* \\ Joint Centre for Mesoscale Meteorology, University of Reading, UK.
}

\begin{abstract}
Centered at the interface between the sea breeze and the return flow aloft, Kelvin-Helmholtz billows (KHB) are an important feature of the turbulent structure of some sea-breeze circulations (SBCs). In other SBCs, there are no prominent KHBs observed. Factors governing the appearance of billows are determined from a database of 139 sea breezes, constructed from two years of summertime surface observations at a site on the south coast of England. Post-frontal oscillations occur in the surface data for some SBCs and are interpreted as indicating possible KHBs aloft. The SBCs are formed under a wide range of synoptic conditions, enabling various measures of possible billow occurrence to be related to properties of the large-scale, ambient flow. Consistent with laboratory experiments of density currents, KHBs are suppressed for propagation into a head wind and enhanced with a tail wind. They are also found to be enhanced for stronger ambient wind speeds, while large-scale coast-parallel flow is effective in suppressing the billows.
\end{abstract}

Keywords: sea breeze, Kelvin-Helmholtz billows, post-frontal oscillations, surface observations.

\section{Introduction}

The sea breeze has been extensively studied through field observations, numerical and analytic modelling and laboratory tank experiments. (Reviews have been presented by Atkinson (1981), Simpson (1994) and Miller et al. (2003).) Nonetheless, important issues remain. In recent years improvements to both observational techniques and numericalmodel resolution have focussed attention on the turbulent structures at the interfaces between marine and land air. Coherent structures occur close to the sea-breeze front (SBF), particularly within the elevated head region (Reible et al., 1993; Simpson, 1994; Atkins et al., 1995), and also between the sea breeze flow itself and the return flow aloft (Sha et al., 1991; Hadi et al., 2000; Lapworth, 2000). The associated mixing (Linden and Simpson, 1986; Hallworth et al., 1996; Wood et al., 1999) is known to have important consequences for the inland propagation of the sea breeze (Buckley and Kurzeja, 1997a; Fovell and Dailey, 2001) and for pollutant dispersal (Simpson and Britter, 1980; Buckley and Kurzeja, 1997b), while the associated vertical motions are important

\footnotetext{
* Current address: Environment Agency, Rivers House, Higher Shaftesbury Road, Blandford Forum, Dorset. DT11 8ST
}

(C) 2006 Kluwer Academic Publishers. Printed in the Netherlands. 
for the initiation of convection (Rao et al., 1999; Rao and Fuelberg, 2000). In this paper, we consider the occurrence of Kelvin-Helmholtz billows (KHB) at the interface between the sea breeze and the return flow. The billows may be a prominent feature of the turbulence and are capable of producing a peak in the power spectrum (Wood et al., 1999).

Turbulence within sea-breeze circulations (SBCs) has been investigated using water-tank experiments of gravity currents. Simpson (1982; 1994) has provided overviews of such studies. An important finding of the laboratory experiments is that a Kelvin-Helmholtz instability occurs just behind the front (Linden and Simpson, 1986). Figure 1 is a schematic illustrating the evolution of the resulting turbulent vortices, based on interpretation of tank experiments ${ }^{1}$ and numerical simulations. Kelvin-Helmholtz instabilities occur where there is strong shear and limited static stability, with the gradient Richardson number (Ri) being required to be less than 0.25 . Turbulent vortices form close to the head region and (viewed from a front-relative frame) propagate backwards away from the front along the interface between the sea breeze and return flow. The billows increase in size as they move away from the front, finally breaking and mixing fluid across the density interface. Growth of the billows occurs despite the fact that the gradient Richardson number may not be critical outside of the initiation region, significant billows having been observed with $\mathrm{Ri}$ values of up to about 1 (Lapworth, 2000; see also Strang and Fernando, 2001).

\{Figure 1 approximately here.\}

KHB have also been simulated in numerical modelling studies of the sea breeze (Sha et al., 1991; 1993; Buckley and Kurzeja, 1997a; 1997b; Rao et al., 1999; Rao and Fuelberg, 2000). Numerical studies have contributed to an understanding of KHB development, as well as raising the possibility of important inter-billow interactions (Rao and Fuelberg, 2000). High resolution is undoubtedly required for realistic simulation of the billows. For example, Buckley and Kurzeja (1997a) were able to produce billow-like structures using a grid length of $500 \mathrm{~m}$, but the billow wavelengths were considerably reduced for a grid length of $100 \mathrm{~m}$, a choice that has been made by other groups. (See also Droegemeier and Wilhelmson (1987) for discussion of some other important numerical sensitivities.)

Direct observational evidence for KHB has recently been described by Buckley and Kurzeja (1997a), Hadi et al. (2000) and Lapworth (2000), who measured the passage of the SBC across a fixed point with

\footnotetext{
1 Snapshots of the vortices can be seen for example in Figure 6 of Simpson (1969), Figure 2 of Linden and Simpson (1986) and Figure 3 of Hallworth et al. (1996).
} 
a $300 \mathrm{~m}$ mast, an L-band boundary-layer radar and a tethered balloon respectively. An important aspect of these recent studies is the ability to obtain vertical profiles through the SBC. The authors have therefore been able to present time-height sections that clearly show the extent and the strength of the billows. Note also that wave motions behind the sea-breeze front have been found in lidar (Nakane and Sasano, 1986) and aircraft observations (Reible et al., 1993; Wood et al., 1999).

\{Table I approximately here.\}

Table I summarizes properties of KHB found within SBCs, as estimated from the literature. There are significant variations in the height of the density interface, and this results in variations in the height at which the billows may be directly perceptible. Nonetheless, it is clear that there are occasions where the KHB are strong enough and low enough to be detectable through oscillations in (near-)surface parameters. The possibilities for using surface data are readily apparent in some of the recently-obtained vertical profiles through SBCs. For example, Figure 14 of Buckley and Kurzeja (1997a) and Figures 3 and 5 of Lapworth (2000) demonstrate that the KHB may extend close to the surface. Indeed, Alpert and Rabinovich-Hadar (2003) have obtained convincing evidence for post-frontal oscillations from a dense network of high-temporal-resolution surface stations in southern Israel. Remarkably, the oscillations were found to persist in composites of eight or nine successive days of summertime data ${ }^{2}$. This reflects the remarkable consistency of the sea-breeze system in this location, the synoptic situation being sufficiently steady for the front to arrive at almost the same time each day. It also shows that for given synoptic conditions the KHB that are presumed to cause the post-frontal oscillations are themselves a consistent structural feature of the sea breeze.

The parameters which have been found to exhibit oscillations, and the corresponding amplitudes, are summarized in Table II. Although there is considerable case-to-case variation, an overall tendency can be seen for oscillation amplitudes to decrease for observing heights towards the ground, away from the centre of the billows. Nonetheless, Table II provides good evidence that oscillations in a number of (near)surface parameters should be observable, as has been argued elsewhere (Simpson and Britter, 1980; Droegemeier and Wilhelmson, 1987; Sha et al., 1991; Alpert and Rabinovich-Hadar, 2003). We noted above that KHB may extend close to the surface, and so on occasion may be directly perceptible. However, indirect detection would appear more

\footnotetext{
${ }^{2}$ Donn et al.'s (1956) observations of pressure oscillations following a SBF are believed to constitute the first documented evidence for KHB (although not then attributed as such) within a SBC. Their paper includes a brief comment that such oscillations were perceptible within monthly means.
} 
likely, with the near-surface parameters responding to KHB aloft. The dynamical mechanisms through which oscillations due to the billows might be transmitted down towards the surface are unclear, although Droegemeier and Wilhelmson (1987) did demonstrate that "associated with each breaking wave is a cyclostrophically balanced pressure minimum" (p1198). The amplitude of the pressure perturbation that might be expected is not known. While Droegemeier and Wilhelmson (1987) found values in the range 0.2 to $2.4 \mathrm{hPa}$, from their two-dimensional numerical simulations of thunderstorm outflows, these are considerably larger than those observed by Donn et al. (1956) and simulated by Sha et al. (1991) for oscillations behind a sea-breeze front (Table II).

\{Table II approximately here.\}

It should be noted that the current understanding of KHB within sea breezes has been informed by research into KHB in other atmospheric contexts. As examples, we note investigations into thunderstorm outflows (Mueller and Carbone, 1987; Droegemeier and Wilhelmson, 1987) and clear-air turbulence (Browning, 1971; Smyth, 2004), as well as waves that occur in slope flows (Monti et al., 2002) and along frontal (Nielsen, 1992) and surface inversions (Merrill, 1977).

To summarize, we consider that there is strong evidence, obtained from a variety of approaches, for the existence of KHB within sea breezes. However, not all sea-breeze circulations appear to support the billows (Buckley and Kurzeja, 1997a; Lapworth, 2000), and there is as yet no guide as to whether or not we can expect to find them in particular real cases. In laboratory experiments, KHB are almost always observed; however, there are good indications that they are relatively suppressed (enhanced) for propagation into a head (with a tail) wind (see for example Figure 1 of Britter and Simpson (1978) or Figure 2 of Simpson and Britter (1980)). Ross (submitted to J. Fluid Mech.) has found the same effect in two-dimensional numerical simulations and offers a theoretical explanation in terms of a linear stability analysis (assuming a weak background flow) for the density interface behind the head region. For a head (tail) wind the linear growth rate is reduced (increased) and disturbances are unstable for a smaller (larger) range of wavelengths.

For sea breezes in the real atmosphere, the effects of ambient wind on KHB occurrence have not been determined. To some extent, this is because previous research into KHB in real sea breezes has been of the case-study type. It is difficult to draw any conclusions about factors governing KHB occurrence from the existing literature: the issue is complicated by the different observational methods used, the possible importance of local factors and the probable relative under-reporting of instances where sea breezes do not support distinct KHB. In this study, 
we investigate a database of some 139 sea breezes detected at a surface site on the south coast of England. Following a description of the data set, the criteria chosen to identify sea breezes (Sec. 2) and possible KHB (Sec. 3) are discussed. In Sec. 4 we investigate relationships between aspects of the ambient flow and the presence of oscillations in surface parameters following the passage of a SBF. Conclusions are presented in Sec. 5.

\section{Database of Sea Breezes}

The site chosen for this study is shown in Figure 2. The "Chimet" system measures weather conditions and sea state and is supported by the RNLI (Royal National Lifeboat Institution) together with local organizations and businesses. It is run by a volunteer organization known as the Chimet Support Group. An automated instrumentation system is attached to Chichester bar beacon approximately $1 \mathrm{~km}$ outside Chichester harbour entrance, on the south coast of England. Of relevance to this study are the wind and temperature data, measured each second, and the pressure data, which are measured each minute. The wind sensors are located $14 \mathrm{~m}$ above mean high-water springs. Fiveminute averages of these variables are transmitted via a radio link to the nearby Hayling Island station of the RNLI. The data are archived and are also made available in real time to the general public via a website, www.chimet.co.uk

\{Figure 2 approximately here.\}

For this study, data are used from April to September of 2003 and 2004. It is unfortunate that are some gaps in the record. Most breaks amount to a single day, or some part of it, and are scattered throughout the summer months. However, we note that there is also a single long break of just over two weeks (from 17 July to 1 August 2003). Nonetheless, data for $92 \%$ of the days are available in full and the data set is able to capture the passage of a substantial number of sea breezes under a wide range of synoptic conditions.

As an example, consider 24 June 2003, a day on which high pressure to the south west of the UK dominated conditions on the south coast, producing light offshore winds and clear skies. The Met Office Unified Model predicted a pronounced sea breeze (Galvin and Dominy, 2003), and its front can be seen passing the observing site at about 1000uTC (Figure 3), when there is a clear jump in wind direction, an increase in wind speed and a decrease in temperature.

\{Figure 3 approximately here.\} 
More generally, sea-breeze fronts were extracted automatically from the data by searching for such jumps, using a similar method to that of Alpert and Rabinovich-Hadar (2003), albeit with some differences in the available variables and in the thresholds used. A mandatory criterion for the arrival of the SBF was that the wind direction must be onshore: i.e., between 100 and $260^{\circ}$, according to local maps. This was found to be particularly helpful in immediately eliminating false alarms arising from other phenomena such as the passage of some synoptic fronts. In addition, our algorithm demanded that three of the following conditions be simultaneously met:

1. a change in wind direction of greater that $40^{\circ}$ within 15 minutes;

2. an increase in wind speed of greater than $0.75 \mathrm{~m} \mathrm{~s}^{-1}$ over 35 minutes;

3. a decrease or stabilization in temperature over 15 minutes; and,

4. a "gustiness" value among the eight largest for the day in question.

The "jumps" required for wind speed and temperature are modest so that the criteria were satisfied not infrequently by modest fluctuations in the raw data. Thus, in an attempt to capture genuine, persistent changes to the conditions on arrival of the front, the criteria for both wind speed and temperature were tested on 5-point (20 minute) running averages. By contrast, the required shift in wind direction proved sufficiently large for averaging to be unnecessary. The "gustiness" variable $G$ is used as an indicator of turbulence intensity, and calculated as in Alpert and Rabinovich-Hadar (2003),

$$
G=\frac{\sqrt{\overline{u^{\prime 2}}}}{\bar{u}}
$$

where the overbar denotes a 20 minute running average and $u^{\prime}$ is the deviation of the 5 minute raw data from $\bar{u}$.

As in other investigations (Chiba, 1993; Alpert and RabinovichHadar, 2003), we find that the arrival of a front can be fit into the shortest time period by specifying that the criteria 2 and 3 be satisfied at the beginning of the requisite change, whereas 1 is satisfied at the end of such a change. Values of the numerical thresholds are somewhat arbitrary but were chosen following extensive experimentation and sensitivity checks. Marginal or suspicious (for example, because of an unusual timing) cases were compared against synoptic charts as a check for false alarms ${ }^{3}$. Relaxing the final set of criteria tended only

\footnotetext{
${ }^{3}$ Keith (2004) describes examples of marginal cases: a false alarm caused by a synoptic front, and a weak sea breeze that was difficult for the algorithm to capture.
}

paper.tex; 2/02/2006; 18:04; p.6 
to increase the false alarms whereas strengthening criteria tended to eliminate apparently genuine cases. A valuable check on our methods comes from the total number of sea breezes identified during each summer: 71 in 2003 and 72 in 2004. These are comparable with Watts' (1965) figure of 75 from a study of sea breezes at nearby Thorney Island (Figure 2(b)).

\section{Recognition of post-frontal oscillations}

Following earlier studies, and as discussed in Sec. 1, oscillations in the data following the arrival of a sea-breeze front will be assumed here to be indicative of the presence of Kelvin-Helmholtz billows.

The 5 minute data for each parameter were automatically plotted for a interval of 90 minutes following each diagnosed SBF arrival. In practice, we have made a Lagrangian transformation to envisage our temporal data for a fixed location as being equivalent to a snapshot of the SBC as a function of distance from the front. The conversion to a distance scale is made using the time-varying component of wind normal to the coastline. For most of the sea breezes identified, such a rescaling of the horizontal plot axis is somewhat cosmetic for the present purposes and has very little impact upon one's perception of any oscillations in the data. However, any major shifts in the wind direction are immediately apparent on such plots and this is desirable in ensuring that some oscillations in the temporal data are not misinterpreted. For example, it would not be reasonable to make use of data recorded following, let us say, a reversal of the wind to the offshore direction 30 minutes after a diagnosed SBF. In such a situation, the subsequent data should not and are not used as an indication of the SBC structure behind the front.

Example plots for the 29 June 2004 are given in Figure 4. Beginning around 20 minutes after the arrival of the front, a sequence of four oscillations can be observed. These are labelled as A to D on the figure and are perhaps most readily apparent in the wind speed (Figure 4(b)). Feature $\mathrm{C}$ is only just perceptible in terms of temperature and direction, while the pressure data captures only a suggestion of feature A. The periods and amplitudes of these oscillations fall within the ranges given in Table II.

\{Figure 4 approximately here.\}

Oscillations in the data can also be seen following other SBFs, although for illustrative purposes the example given above is a rather clean case. Typically one might identify two or three possible oscillations, each "feature" being composed of two or three data points. Not 
uncommonly, however, the oscillations are found in only a subset of the data parameters and any phase relationships between parameters are generally much less clear. Thus, while the data set as a whole provides convincing evidence for post-frontal oscillations, it is not always straightforward to be definitive in a particular case.

Recognizing that there is a significant subjective element involved in assessing the presence of oscillations, we have developed a confidence index. The construction of this measure allows valuable checks to be made on any sensitivities to issues of judgement. A decision has to be taken about whether or not there are oscillations in the plot of each parameter following each SBF. In a straightforward situation with clear features (as in Figure 4(a)-(c), for instance) a score of 2 is assigned. With no or very little evidence to suggest oscillations (as in Figure 4(d)), the score is 0 . Finally, a score of 1 is given in intermediate cases where there are some indications but not-entirely-satisfactory evidence for oscillations. In practice $16 \%$ of plots fell under this category (Table III has a breakdown by data parameter). The usual reasons for a score of 1 are either a somewhat unconvincing wave amplitude or else an insufficient number of data points comprising the possible features. The scores assigned for the four parameters of pressure, temperature, wind speed and direction are then summed to produce a KHB index value, labelled KHI, for use in later analysis. A default threshold for the KHI has been taken to be 4 : this is equivalent to finding clear oscillations in two separate parameters or to finding some evidence for oscillations in all four parameters.

\{Table III approximately here.\}

The frequency distribution of the KHI is given in Figure 5. If the default threshold is taken then oscillations are considered to occur on $63 \%$ of occasions. However, this value should not be interpreted too literally: this surface-based data set is certainly not sufficient to derive an overall probability of KHB occurrence. Adjustment of the KHI threshold to 3 or 5 alters the proportion of events significantly to $79 \%$ or $32 \%$ respectively. Nonetheless, we contend that it is reasonable to use the data to look for relationships between KHB occurrence and parameters representative of the ambient, large-scale conditions. If a postulated relationship is able to survive a change in definition of KHB occurrence between threshold KHI values of 3 and 5, then the relevant large-scale parameter can be regarded as a useful qualitative indicator of KHB occurrence.

\{Figure 5 approximately here.\}

The usefulness of a particular parameter for the detection of postfrontal oscillations depends upon the nature of the parameter, the precision of its measurement and the averaging used. Contributions to 
the KHI from each parameter in the current data set are summarized in Table III. Also given are mean scores for each parameter averaged over sea breezes for which the KHI does or does not meet the default threshold. The difference between these two mean scores provides a measure of the utility of the parameter for KHB detection within this data set. Pressure (reported to $\pm 0.1 \mathrm{hPa}$ ) oscillations are rarely found, presumably because the measurements are not sufficiently precise for the purpose. This is consistent with Donn et al. (1956) and Sha et al. (1991), and confirms that the simulations of Droegemeier and Wilhelmson (1987) are not representative of the pressure perturbations from KHBs within a SBC (see Sec. 1$)$. The temperature $( \pm 0.1 \mathrm{~K})$ and wind $\left( \pm 0.1 \mathrm{~m} \mathrm{~s}^{-1}\right.$ and $\left.\pm 1^{\circ}\right)$ data, however, do provide useful discriminants. To some extent they may play complementary roles in the identification since the distribution of scores by parameter suggests that the temperature data are not precise enough to detect some of the billows and/or that false alarms occur in the wind data.

\section{Results}

Relationships have been sought between the ambient conditions and the occurrence of oscillations following a SBF. Grouping together the sea breezes according to ambient conditions, there are of course many possibilities for translating a set of KHI values into an overall measure for the group. One option is simply to take the mean KHI ( $\overline{\mathrm{KHI}})$. Another is to derive a "probability" of KHB occurrence. If a threshold $\mathrm{KHI}$ is set at $T$ then the fraction of sea breezes meeting the threshold produces a probability $P_{T}$. As discussed in Secs. 1 and 3 there are significant uncertainties in the determination of billow occurrence from surface data, and it is therefore important to make thorough sensitivity tests of any apparent relationships. We do not present here all of the checks ${ }^{4}$ made, but results for $\overline{\mathrm{KHI}}, P_{3}, P_{4}$ and $P_{5}$ are provided.

In Sec. 1 we discussed the suggestion from laboratory experiments that KHB are less prominent if a gravity current is propagating into a head wind rather than with a tail wind. One might anticipate some dependence on the wind strength as well as its orientation and so we have examined the effects of wind orientation (Table IV) and speed (Table V). Quantities characterizing the ambient wind have been taken from data one hour before the diagnosed arrival time of the front. This time is short enough for data to be genuinely representative of

\footnotetext{
4 As an example, we have checked explicitly that the conclusions are not affected whether or not the pressure data are taken into account.
} 
conditions beforehand and yet long enough not to be sensitive to any errors in determining the arrival time of the front.

\{Table IV approximately here.\}

\{Table V approximately here.\}

Table IV shows the relationship to wind orientation, specifically the wind rotation during SBF passage. A very similar relationship can be discerned using simply the data for wind direction prior to SBF arrival. However, somewhat cleaner results are produced in terms of the rotation; hence its appearance here. The rotation is defined as the magnitude of the shift in direction between one hour before and one hour after the SBF arrival. Thus, a small rotation corresponds to an ambient tail wind, while values of 90 or $180^{\circ}$ correspond to coast-parallel or head winds respectively. For each of the various measures of KHB occurrence, it is clear that the likelihood of KHB is greatest with a tail wind and decreases significantly for coast-parallel flow. Interestingly, the KHB likelihood in a head wind appears to be slightly greater than in the coast-parallel case, although this point is not clear in all of the measures.

The results in Table IV are certainly encouraging in support of the postulated effect of ambient wind, but are not in themselves conclusive. This site on the south coast of England experiences a wide range of synoptic conditions and is thus well-suited to the present study. However, the ambient winds are not symmetrically distributed, with flow from the south-west (onshore) being climatologically favourable. Moreover, in addition to being less frequent, ambient offshore winds are weaker on the average than their onshore counterparts. Table $\mathrm{V}$ therefore raises the possibility of an alternative interpretation. It indicates that KHB are more likely for stronger ambient wind speeds. Thus, it seems possible that the trend in Table IV might not be universal but rather an artefact of the wind speed trend allied to local climatology ${ }^{5}$.

To test this point, in Table VI we have taken the results for head and tail winds from Table IV and subdivided them into events with low and high ambient wind speed. The combined results can only be explained if both of the trends in wind speed and orientation identified above are genuine: there is an increase in likelihood for stronger ambient winds, and an asymmetry between head and tail winds due to the orientation effect.

\{Table VI approximately here.\}

\footnotetext{
${ }^{5}$ Contrariwise, of course, one could just as well imagine the orientation relationship to be genuine and the apparent wind speed relationship to arise through the combination of the orientation trend and climatology.
} 


\section{Conclusions}

Previous observational and modelling studies have found Kelvin-Helmholtz billows of significant amplitude in the region of strong shear at the top of a density current. The billows are important aspects of the structure and evolution of the density current and its interaction with its environment. In sea breeze circulations, KHB have been observed using a variety of techniques, and have been associated with oscillations in surface parameters after the arrival of a sea-breeze front. However, billows are not observed for all SBCs. Here we have constructed a database of sea breezes formed under a wide range of synoptic conditions in order to examine the effects of ambient flow on billow occurrence.

Laboratory experiments have suggested that billows are suppressed for a density current propagating into a head wind and enhanced with a tail wind. Our analysis of post-frontal surface oscillations supports the suggestion. Moreover, further support has recently been provided by Ross (submitted to J. Fluid Mech.) from analytic and numerical modelling of density currents. Although the detection of billows from oscillations in surface data is sometimes marginal (at least for data with the precision and frequency available here), sensitivity tests on the definition of billow occurrence do provide a degree of confidence in the results. Since the relevant laboratory and numerical experiments deal with simplified arrangements that neglect important factors in the development of real sea breezes (e.g., ambient stratification, coastline shape, cross winds) we consider the results obtained to be most valuable. Furthermore, the present analysis has suggested two additional relationships: that the formation of distinct billows is (i) enhanced for stronger ambient flow and (ii) suppressed in coast parallel flow. These new suggestions merit further study, perhaps through the analysis of more observational data, or else in a series of numerical experiments.

\section{References}

Alpert, P. and M. Rabinovich-Hadar: 2003, 'Pre- and post-sea-breeze frontal lines - A Meso- $\gamma$-scale analysis over South Israel'. J. Atmos. Sci. 60, 2994-3008.

Atkins, N. T., R. M. Wakimoto, and T. M. Weckerth: 1995, 'Observations of the sea-breeze from during CaPE. 2. Dual-Doppler and aircraft analysis'. Mon. Wea. Rev. 123, 1374-1393.

Atkinson, B. W.: 1981, Mesoscale Atmospheric Circulations. Academic Press, London. 495pp.

Britter, R. E. and J. E. Simpson: 1978, 'Experiments on the dynamics of a gravity current head'. J. Fluid Mech. 88, 223-240. 
Browning, K. A.: 1971, 'Structure of the atmosphere in the vicinity of largeamplitude Kelvin-Helmholtz billows'. Quart. J. Roy. Meteorol. Soc. 97, 283-299.

Buckley, R. L. and R. J. Kurzeja: 1997a, 'An observational and numerical study of the nocturnal sea breeze. Part I: Structure and circulation'. J. Appl. Meteorol. 36, 1577-1598.

Buckley, R. L. and R. J. Kurzeja: 1997b, 'An observational and numerical study of the nocturnal sea breeze. Part II: Chemical transport'. J. Appl. Meteorol. 36, 1599-1619.

Chiba, O.: 1993, 'The turbulent characteristics in the lowest part of the sea breeze front in the atmospheric surface layer'. Boundary-Layer Meteorol. 65, 181-195.

Donn, W. L., P. L. Miltic, and R. L. Brilliant: 1956, 'Gravity waves and the tropical sea breeze'. J. Meteorol. 13, 356-361.

Droegemeier, K. K. and R. E. Wilhelmson: 1987, 'Numerical simulation of thunderstorm outflow dynamics. Part 1: Outflow sensitivity experiments and turbulence dynamics'. J. Atmos. Sci. 44, 1180-1210.

Fovell, R. G. and P. S. Dailey: 2001, 'Numerical Simulation of the Interaction Between the Sea-Breeze Front and Horizontal Convective Rolls. Part II: Alongshore ambient flow'. Mon. Wea. Rev. 129, 2057-2072.

Galvin, J. and P. Dominy: 2003, 'Weather Image — Sea-breezes'. Weather 59, 28.

Hadi, T. W., T. Tsuda, H. Hashiguchi, and S. R. Fukao: 2000, 'Tropical sea-breeze circulation and related atmospheric phenomena observed with L-band boundary layer radar in Indonesia'. J. Meteor. Soc. Japan 78, 123-140.

Hallworth, M. A., H. E. Huppert, J. C. Phillips, and S. J. Sparks: 1996, 'Entrainment into two dimensional and axisymmetric turbulent gravity currents'. J. Fluid Mech. 308, 289-311.

Keith, G. J.: 2004, 'An analysis of sea breezes on the south coast of England and evidence of pre- and post-frontal waves at the surface'. Master's thesis, Department of Meteorology, University of Reading. 74pp.

Lapworth, A.: 2000, 'Observations of atmospheric density currents using a tethered balloon-borne turbulence probe system'. Quart. J. Roy. Meteorol. Soc. 126, 2811-2850.

Linden, P. F. and J. E. Simpson: 1986, 'Gravity-driven flows in a turbulent fluid'. J. Fluid Mech. 172, 481-497.

Merrill, J. T.: 1977, 'Observational and theoretical study of shear instability in the airflow near the ground'. J. Atmos. Sci. 34, 911-921.

Miller, S. T. K., B. D. Keim, R. W. Talbot, and H. A. Mao: 2003, 'Sea breeze: Structure, forecasting, and impacts'. Rev. Geophys. 41, art. no. 1011.

Monti, P., H. J. S. Fernando, M. Princevac, W. C. Chan, T. A. Kowalewski, and E. R. Pardyjak: 2002, 'Observations of flow and turbulence in the nocturnal boundary layer over a slope'. J. Atmos. Sci. 59, 2513-2534.

Mueller, C. K. and R. E. Carbone: 1987, 'Dynamics of a thunderstorm outflow'. J. Atmos. Sci. 44, 1879-1898.

Nakane, H. and Y. Sasano: 1986, 'Structure of a sea-breeze front revealed by scanning lidar observation'. J. Meteor. Soc. Japan 64, 789-792.

Nielsen, J. W.: 1992, 'In-situ observations of Kelvin-Helmholtz waves along a frontal inversion'. J. Atmos. Sci. 49, 369-386.

Rao, P. A. and H. E. Fuelberg: 2000, 'An investigation of convection behind the Cape Canaveral sea-breeze front'. Mon. Wea. Rev. 128, 3437-3458.

paper.tex; 2/02/2006; 18:04; p.12 
Rao, P. A., H. E. Fuelberg, and K. K. Droegemeier: 1999, 'High-resolution modelling of the Cape Canaveral land-water circulations and associated features'. Mon. Wea. Rev. 127, 1808-1821.

Reible, D. D., J. E. Simpson, and P. F. Linden: 1993, 'The sea breeze and gravitycurrent frontogenesis'. Quart. J. Roy. Meteorol. Soc. 119, 1-16.

Sha, W., T. Kawamura, and H. Ueda: 1991, 'Numerical study on sea/land breezes as a gravity current: Kelvin-Helmholtz billows and inland penetration of the sea-breeze front'. J. Atmos. Sci. 48, 1649-1665.

Sha, W., T. Kawamura, and H. Ueda: 1993, 'A numerical study of nocturnal sea breezes - Prefrontal gravity-waves in the compensating flow and inland penetration of the sea-breeze cut-off vortex'. J. Atmos. Sci. 50, 1076-1088.

Simpson, J. E.: 1969, 'A comparison between laboratory and atmospheric density currents'. Quart. J. Roy. Meteorol. Soc. 95, 758-765.

Simpson, J. E.: 1982, 'Gravity currents in the laboratory, atmosphere and ocean'. Ann. Rev. Fluid Mech. 14, 213-234.

Simpson, J. E.: 1994, Sea Breeze and Local Winds. Cambridge University Press. $234 \mathrm{pp}$.

Simpson, J. E. and R. E. Britter: 1980, 'A laboratory model of an atmospheric mesofront'. Quart. J. Roy. Meteorol. Soc. 106, 485-500.

Smyth, W. D.: 2004, 'Kelvin-Helmholtz billow evolution from a localized source'. Quart. J. Roy. Meteorol. Soc. 130, 2753-2766.

Strang, E. J. and H. J. S. Fernando: 2001, 'Entrainment and mixing in stratified shear flows'. J. Fluid Mech. 428, 349-386.

Watts, A.: 1965, Wind and sailing boats: The structure and behaviour of the wind as it affects sailing craft. Adlard Coles, London. 224pp.

Wood, R., I. M. Stromberg, and P. R. Jonas: 1999, 'Aircraft observations of seabreeze frontal structure'. Quart. J. Roy. Meteorol. Soc. 125, 1959-1995. 


\section{Tables}

Table I. Properties of various KHB found within SBCs (observed, modelled in the laboratory or simulated numerically), estimated by the authors from data and figures in the literature. Where a range is stated this may originate from multiple billows observed or else to the same billow at different stages in its lifecycle. The "lowest height" is an estimate of the closest position to the surface at which direct effects of the billow were perceptible in the published figures. Under this column an entry of zero indicates that a billow extended close $(\lesssim 20 \mathrm{~m})$ to the surface.

\begin{tabular}{lcccc}
\hline Reference & Method & $\begin{array}{c}\text { Central } \\
\text { height (m) }\end{array}$ & $\begin{array}{c}\text { Lowest } \\
\text { height (m) }\end{array}$ & $\begin{array}{c}\text { Wavelength } \\
\text { or period }\end{array}$ \\
\hline Donn et al. (1956) & Surface obs & - & - & $5-40 \mathrm{~min}$ \\
Britter and Simpson (1978) & Laboratory & - & 0 & - \\
Nakane and Sasano (1986) & Lidar & - & - & $2 \mathrm{~km}$ \\
Sha et al. (1991) & Simulated & 300 & - & $0.5-3 \mathrm{~km}$ \\
Reible et al. (1993) & Aircraft & - & - & $1-1.5 \mathrm{~km}$ \\
Buckley and Kurzeja (1997a) & Tower & 80 & 0 & - \\
Buckley and Kurzeja (1997a) & Simulated & $100-400$ & $100-150$ & $1-2 \mathrm{~km}$ \\
Rao et al. (1999) & Simulated & $60-120$ & 0 & $0.5-2.5 \mathrm{~km}$ \\
Rao and Fuelberg (2000) & Simulated & $350-500$ & $300-350$ & $0.5-2 \mathrm{~km}$ \\
Hadi et al. (2000) & Radar & $900-1400$ & 800 & $30 \mathrm{~min}$ \\
Lapworth (2000) & Tethered balloon & $100-400$ & $0-150$ & $0.5-1 \mathrm{~km}$ \\
\hline
\end{tabular}

paper.tex; 2/02/2006; 18:04; p.14 
Table II. Oscillations in various parameters due to KHB found within sea-breeze circulations, estimated by the authors from data and figures in the literature. Where a range is given this may refer to multiple billows observed or else to the same billow at different stages in its lifecycle. The parameters are: $\mathrm{P}$ - pressure; $\mathrm{T}$ - temperature; $\mathrm{q}$ - specific humidity; $\mathrm{RH}$ - relative humidity; $\mathrm{w}$ vertical velocity; WD - wind direction; WS - wind speed.

\begin{tabular}{|c|c|c|c|}
\hline Reference & Method & $\begin{array}{l}\text { Height }(\mathrm{m}) \text { of } \\
\text { observations }\end{array}$ & $\begin{array}{l}\text { Oscillation } \\
\text { amplitude }\end{array}$ \\
\hline Donn et al. (1956) & Surface obs & 0 & $\mathrm{P}: 0.8 \mathrm{~Pa}$ WS:2-3 $\mathrm{m} \mathrm{s}^{-1}$ \\
\hline Sha et al. (1991) & Simulated & 220 & $\mathrm{P}: 0.5 \mathrm{~Pa}$ WS:0.5 $\mathrm{m} \mathrm{s}^{-1}$ \\
\hline Sha et al. (1991) & Simulated & 300 & WS:0.5 $\mathrm{m} \mathrm{s}^{-1}$ \\
\hline Reible et al. (1993) & Aircraft & 500 & $\mathrm{q}: 0.5 \mathrm{~g} \mathrm{~kg}^{-1} \mathrm{~T}: 0.4 \mathrm{~K}$ \\
\hline Wood et al. (1999) & Aircraft & 470 & $\mathrm{w}: 1 \mathrm{~m} \mathrm{~s}^{-1} \mathrm{WS}: 2 \mathrm{~m} \mathrm{~s}^{-1}$ \\
\hline Wood et al. (1999) & Aircraft & 630 & $\mathrm{q}: 1 \mathrm{~g} \mathrm{~kg}^{-1} \mathrm{~T}: 1 \mathrm{~K}$ \\
\hline Rao et al. (1999) & Simulated & 100 & $\mathrm{w}: 0.4 \mathrm{~m} \mathrm{~s}^{-1}$ \\
\hline Lapworth (2000) & Tethered balloon & 150 & $\mathrm{q}: 0.25 \mathrm{~g} \mathrm{~kg}^{-1} \mathrm{~T}: 0.3-0.5 \mathrm{~K}$ \\
\hline Alpert and & Surface obs & 0 & T:0.1-0.3 K RH:0.5\% \\
\hline Rabinovich-Hadar (2003) & & & $\mathrm{WD}: 10-20^{\circ} \mathrm{WS}: 0.3-0.5 \mathrm{~m} \mathrm{~s}^{-1}$ \\
\hline Alpert and & Tower & 60 & $\mathrm{RH}: 1 \% \mathrm{WD}: 10^{\circ}$ \\
\hline Rabinovich-Hadar (2003) & & & WS: $0.2 \mathrm{~m} \mathrm{~s}^{-1}$ \\
\hline
\end{tabular}

Table III. A breakdown of the confidence scores assigned for each data parameter. As described in the main text, a score of 2 is assigned for clear evidence of oscillations, a score of 0 for no apparent evidence and a score of 1 in ambiguous cases. The first three numerical columns record the fraction of cases for which a particular score is assigned (with the total number of cases in parenthesis). The final two columns list mean scores in the presence or absence of KHB, assuming a threshold of 4 for the KHI.

\begin{tabular}{lccccc}
\hline Parameter & Score=0 & Score=1 & Score=2 & Mean with KHB & Mean if no KHB \\
\hline Pressure & $0.88(123)$ & $0.06(9)$ & $0.05(7)$ & 0.18 & 0.14 \\
Temperature & $0.58(80)$ & $0.23(32)$ & $0.19(27)$ & 0.88 & 0.18 \\
Wind speed & $0.18(25)$ & $0.14(20)$ & $0.68(94)$ & 1.84 & 0.90 \\
Wind direction & $0.18(25)$ & $0.19(26)$ & $0.63(88)$ & 1.89 & 0.71 \\
\hline Overall & $0.46(253)$ & $0.16(87)$ & $0.39(216)$ & 1.20 & 0.48 \\
\hline
\end{tabular}


Table IV. Measures of the likelihood of KHB occurrence are tabulated against the orientation of the ambient wind, measured in terms of the rotation angle. The rotation is the magnitude of the change in wind direction between one hour before and one hour after the SBF arrival. Tail, coast-parallel and head winds correspond to rotation angles in the ranges $0-60^{\circ}, 60-120^{\circ}$ and $120-180^{\circ}$ respectively. $\overline{\mathrm{KHI}}$ is a mean value of the KHI indicator, and the total number of cases with winds of each orientation is given in parenthesis. The $P_{T}$ give the probabilities that sea breezes for that orientation exceed a threshold KHI. The number of cases for which the threshold is met are given in parenthesis.

\begin{tabular}{lccc}
\hline & Tail wind & Parallel wind & Head wind \\
\hline$\overline{\text { KHI }}$ & $4.21(78)$ & $3.00(25)$ & $3.22(36)$ \\
$P_{3}$ & $0.87(68)$ & $0.68(17)$ & $0.69(25)$ \\
$P_{4}$ & $0.76(59)$ & $0.40(10)$ & $0.53(19)$ \\
$P_{5}$ & $0.41(32)$ & $0.20(5)$ & $0.22(8)$ \\
\hline
\end{tabular}

Table V. As for Table IV, with the likelihood measures tabulated against the wind speed one hour before SBF arrival. Low and high winds correspond to speeds smaller and larger than $2.85 \mathrm{~m} \mathrm{~s}^{-1}$ respectively, a choice which split the data set evenly between the two categories.

\begin{tabular}{lcc}
\hline & Low winds & High winds \\
\hline$\overline{\mathrm{KHI}}$ & $3.08(69)$ & $4.37(70)$ \\
$P_{3}$ & $0.64(44)$ & $0.94(66)$ \\
$P_{4}$ & $0.48(33)$ & $0.79(55)$ \\
$P_{5}$ & $0.25(17)$ & $0.40(28)$ \\
\hline
\end{tabular}

Table VI. As for Table IV, with the likelihood measures tabulated against both the wind orientation (head or tail, as in Table IV) and the wind strength (low or high, as in Table V).

\begin{tabular}{lcccc}
\hline & \multicolumn{2}{c}{ Tail wind } & \multicolumn{2}{c}{ Head wind } \\
& High speed & Low speed & Low speed & High speed \\
\hline$\overline{\mathrm{KHI}}$ & $4.38(37)$ & $4.05(41)$ & $2.60(15)$ & $3.67(21)$ \\
$P_{3}$ & $0.92(34)$ & $0.83(34)$ & $0.53(8)$ & $0.81(17)$ \\
$P_{4}$ & $0.78(29)$ & $0.73(30)$ & $0.47(7)$ & $0.57(12)$ \\
$P_{5}$ & $0.43(16)$ & $0.39(16)$ & $0.13(2)$ & $0.29(6)$ \\
\hline
\end{tabular}




\section{Figures}

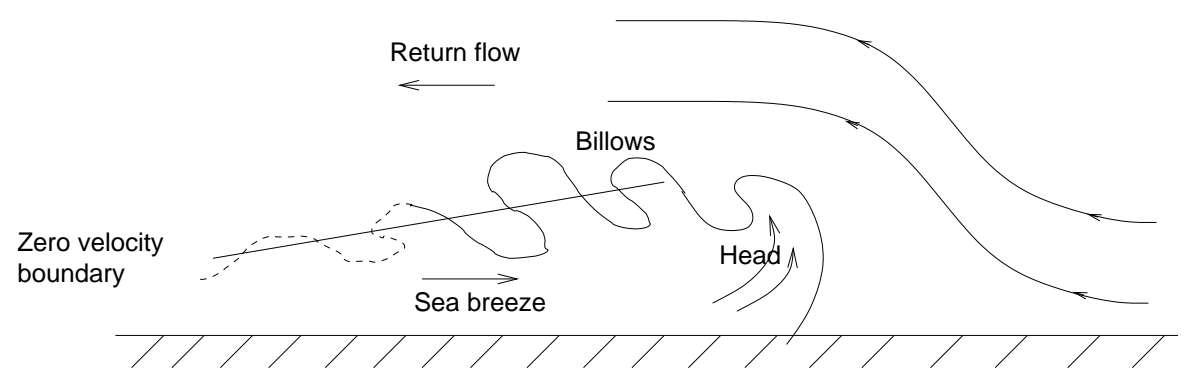

Figure 1. Schematic illustrating the development of Kelvin-Helmholtz billows behind a sea-breeze front. The billows grow, reach maturity and eventually break as they propagate backwards away from the front, and are centered along the zero-velocity boundary separating the sea breeze and the return current. The dotted line on the schematic denotes billows which are breaking down.

b)

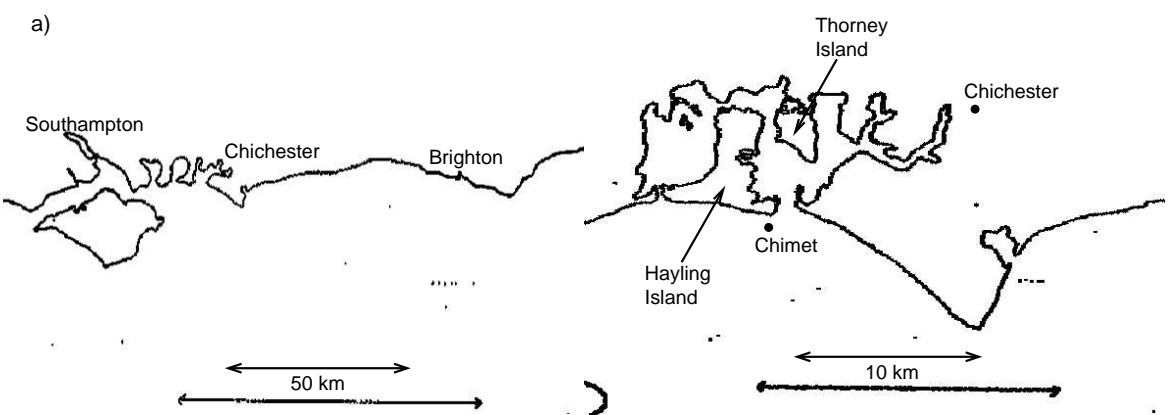

Figure 2. Maps showing the location of (a) Chichester on the south coast of England, and (b) Chichester harbour and its surrounding area. Marked on (b) is the location of the Chimet observation site. 

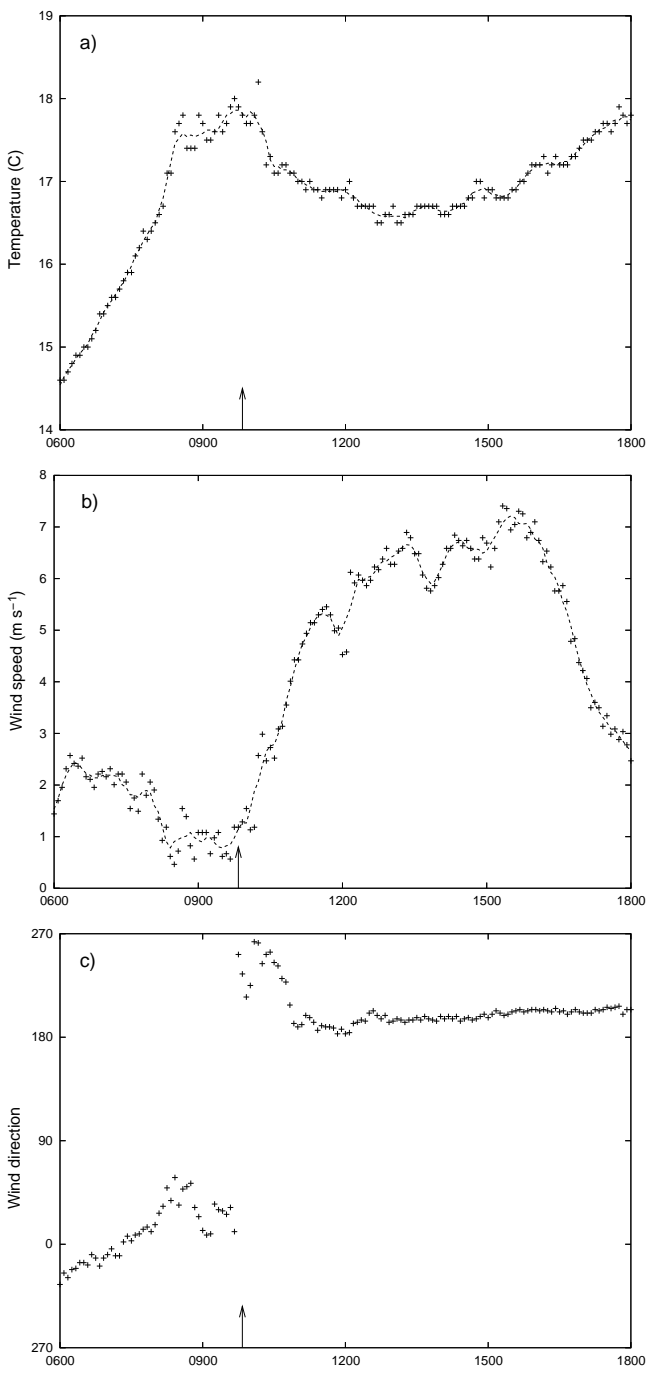

Figure 3. Time series (with time expressed as UTC) of (a) temperature, (b) wind speed and (c) wind direction observed on 24 June 2003. For (a) and (b) the raw 5 -minute data are plotted with crosses along with the 20 minute running average as a line. For (c), only the raw 5 minute data are plotted. The arrow at 0950utc marks the arrival of the sea-breeze front according to the identification scheme described in the text. 

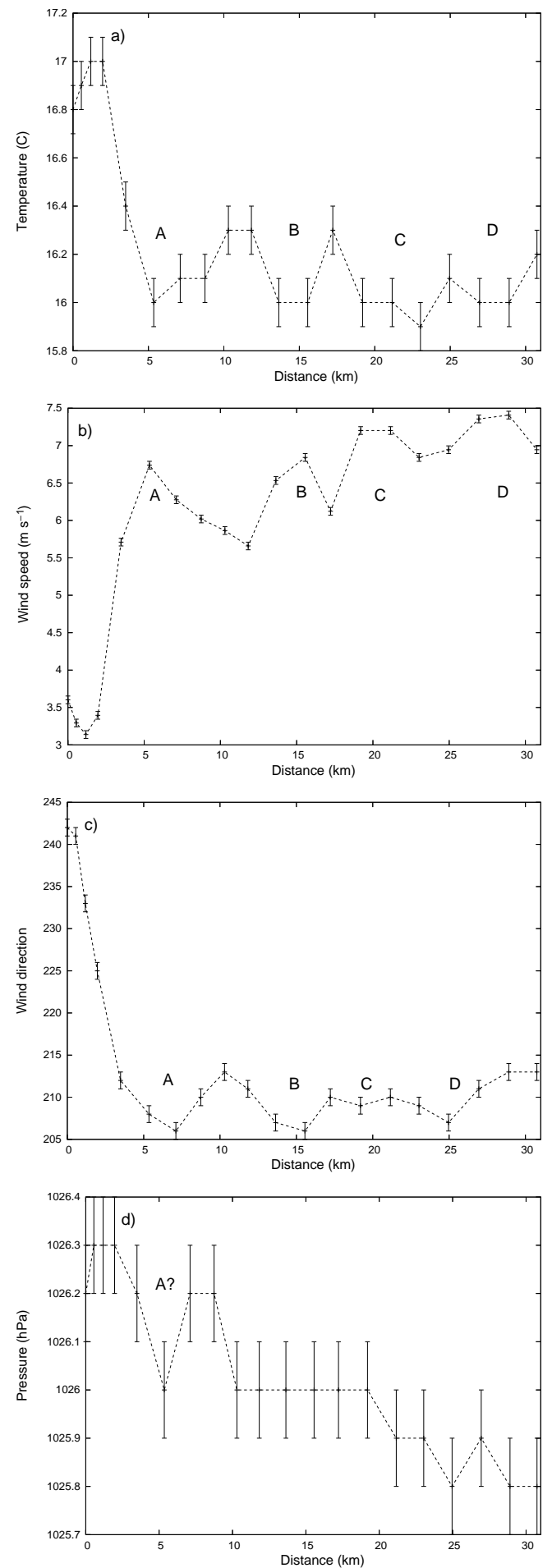

Figure 4. The (a) temperature, (b) wind speed, (c) wind direction and (d) pressure observed following the arrival of a SBF on 29 June 2004. 5 minute data are plotted with error bars corresponding to the precision with which the data are reported. The distance is that normal to the coastline. 


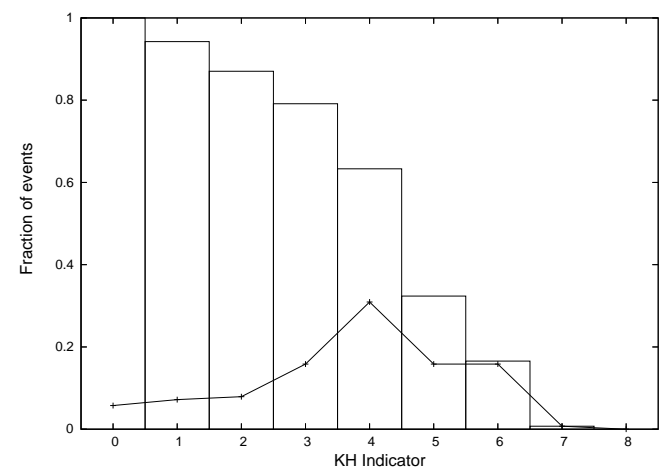

Figure 5. Distribution of the KHB index, KHI. The solid line shows the proportion of sea breezes with that KHI value. The histogram shows the proportion of sea breezes that would be classified as having oscillations for a given KHI threshold. 
Address for Offprints: Department of Meteorology,

University of Reading,

Reading.

RG6 6BB

UK

e-mail: r.s.plant@rdg.ac.uk

Phone: +44 1183785587

Fax: +44 1183788905

paper.tex; 2/02/2006; 18:04; p.21 
paper.tex; 2/02/2006; 18:04; p.22 